This article was downloaded by: [National Taiwan University], [Herng-Dar Bih] On: 23 November 2011, At: 17:38

Publisher: Routledge

Informa Ltd Registered in England and Wales Registered Number: 1072954 Registered

office: Mortimer House, 37-41 Mortimer Street, London W1T 3J H, UK

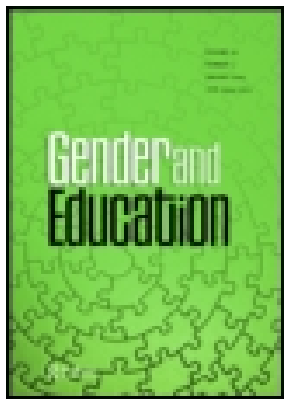

\title{
Gender and Education
}

Publication details, including instructions for authors and subscription information:

http:// www.tandfonline.com/loi/ cgee20

\section{Aluba and 'high' culture: adolescent male peer culture in play}

\author{
Herng-Dar Bih ${ }^{a} \&$ Haitao Huang ${ }^{b}$ \\ ${ }^{a}$ Graduate Institute of Building and Planning, National Taiwan \\ University, Taipei, Taiwan \\ ${ }^{b}$ Department of Chinese Language and Literature, Sun Yat-sen \\ University, China
}

Available online: 23 Nov 2011

To cite this article: Herng-Dar Bih \& Haitao Huang (2011): Aluba and 'high' culture: adolescent male peer culture in play, Gender and Education, DOI: 10.1080/ 09540253.2011.602330

To link to this article: http:// dx.doi.org/ 10.1080/ 09540253.2011.602330

\section{GFirst}

\section{PLEASE SCROLL DOWN FOR ARTICLE}

Full terms and conditions of use: http://www.tandfonline.com/page/terms-andconditions

This article may be used for research, teaching, and private study purposes. Any substantial or systematic reproduction, redistribution, reselling, loan, sub-licensing, systematic supply, or distribution in any form to anyone is expressly forbidden.

The publisher does not give any warranty express or implied or make any representation that the contents will be complete or accurate or up to date. The accuracy of any instructions, formulae, and drug doses should be independently verified with primary sources. The publisher shall not be liable for any loss, actions, claims, proceedings, demand, or costs or damages whatsoever or howsoever caused arising directly or indirectly in connection with or arising out of the use of this material. 


\title{
Aluba and 'high' culture: adolescent male peer culture in play \\ Herng-Dar Bih ${ }^{\mathrm{a} *}$ and Haitao Huang ${ }^{\mathrm{b}}$ \\ ${ }^{a}$ Graduate Institute of Building and Planning, National Taiwan University, Taipei, Taiwan; \\ ${ }^{b}$ Department of Chinese Language and Literature, Sun Yat-sen University, China
}

(Received 27 April 2010; final version received 26 April 2011)

\begin{abstract}
Aluba is a campus activity popular among adolescent males in Taiwan in which four boys lift up another boy by his arms and legs and make a show of pushing or rubbing his genitals against a pole-shaped object. The 'alubaee', nearly always a willing participant, is expected to put up a show of resistance for the satisfaction of all involved. It is a type of play for males that promotes closeness as well as competition. This study combines interviews, photographs and video materials with experiential descriptions to describe the aluba process, and analyses the fluidity of participant roles, the subtleties of the interaction among males, and the specific meaning of 'high' culture of adolescent males as reflected in the process of aluba.
\end{abstract}

Keywords: social psychology; cultural studies; masculinities; youth culture; qualitative interviews; secondary education; South-East Asia

\section{Introduction}

In Taiwanese high schools, aluba is an activity popular among adolescent boys in which three or four boys grab another by his arms and legs, spread his legs, and make a play of pushing the 'victim's' genitals against a pole or other solid object. The person being 'alubaed' has to symbolically struggle and howl, while onlookers cheer to generate greater excitement. Aluba has become so popular in high schools that students have built a glossary with more than 100 vocabulary items related to aluba, such as alubaphobia, misaluba, alubamate. A locally popular band has written a song called 'Aluba Dysentery', and many high schools have been forced to explicitly prohibit the practice.

Through in-depth interviews and image text analysis, this paper attempts to provide an understanding of how and why aluba occurs, along with participant role classification and behaviour. This study further analyses how boys construct masculinity and homosociability during aluba, the position of girls in aluba, and the role of aluba in Taiwan's high school education system. The researchers believe that aluba is not typical bullying. Rather, it is a game played by a group of good friends to show friendship and seek excitement in the context of a highly disciplined school environment.

\section{Literature review}

Most contemporary gender theories (e.g. Johnson 2005) have rejected essentialism and gender role theory. Essentialism proposed that gender and gender-based practices were

\footnotetext{
*Corresponding author. Email: hdbih@ntu.edu.tw
} 
determined solely by natural physiological characteristics, entirely dismissing sociocultural factors. However, gender role theory over-emphasised gender dichotomy and the compliance to and internalisation of gender conventions by individuals within society by ignoring the active role the individual plays during his or her gender learning process. Connell $(2002,2005 \mathrm{a}, 2005 \mathrm{~b})$ departed from the gender relation approach and suggested that gender did not predate society. Instead, gender was constructed within a social context. Thus, masculinities do not exist naturally, nor are they possessed only by men. They are a set of gender practices that concerns gender order. Seidler also pointed out that 'masculinity cannot be taken for granted, but must be constantly defended' $(2006,144)$. Masculinities are plural, and can be constructed differently under different socio/cultural/historical conditions. There is not universal masculinity. Different masculinities can even be found within the same group or organisations. Furthermore, these masculinities are not positioned on the same level, but rather have specific hierarchical differences. Some masculinities were praised (such as hegemonic masculinity), some were devalued (such as homosexual masculinity), and some were marginalised (such as masculinity in ethnic minorities). These different types of masculinity could affect one another and effect dynamic changes.

Connell's theory of masculinities also opened up a new field of gender studies in education. The new studies revealed how the school environment reflected and produced gender identity. Gilbert and Gilbert (1998) identified four territories of masculinising practices in school: (1) school management, policy, and organisation; (2) formal curriculum; (3) physical education and sporting activities; and (4) the relationships between the teachers and students. Swain (2005) further added the relationship between students as a fifth territory. Swain believed that perhaps male peer groups are the most essential social setting in schools. Peer culture acts as an agent to shape masculinities, and exerts peer pressure on individual males to perform in a way that matches the expected group norm. Every peer group possesses a specific culture with shared values and interests. Peer groups also provide a group definition of 'What should males be like'. Peers have a greater impact on male identity than parents do. Males learn how to imitate their peers in this informal peer culture to avoid being ridiculed or bullied by other males. In short, schools perform as an organisation that produces masculinities, but not by direct control. The construction of masculinities actually involves a process that involves negotiation, refusal, acceptance, and contradictions.

School is the place of doing gender for students (West and Zimmerman 1987), which inevitably involves lived bodies (Connell 2002). Young (2005) stressed that the past research has detached bodily factors, while simplifying sex and gender into opposed binary concepts, and the complex processes of individuals acting as active subjects in a gender relationship were being ignored. Youdell (1995) believed that sex-gender-sexuality becomes an integrated whole during students' daily practices (including physical behaviour, play, and clothing), which shape subjective identity. To establish dominant masculinities in schools, boys try to keep distant from females (Nardi 1992), endure risks (Seidler 2006), and gather together in gangs to exercise control over space (Whitehead 2002). Boys also supervise one another's behaviour. Mac an Ghaill (1994) further clarified the three main cultural elements of construction of subjects for heterosexual male students: (1) compulsory heterosexuality, (2) misogyny, and (3) homophobia. These elements are achieved through gender boundary maintenance, supervision, and justification of heterosexual male 
identification. Thus, the heterosexual male is certainly involved in dual relationships: (1) the external relationship - to abuse females and homosexuals, and (2) the internal relationship - remove femininity and homosexual desires. Gender studies, thus, need to focus on the complexity and intertwining of these elements as a specifically organised form of sex/gendered power, especially in terms of gender boundary maintenance, (supervision of) heterosexual male subjects, and legitimisation processes.

This study tries to understand why aluba is prevalent in high schools in Taiwan. What are the role classification, timing, and the process of aluba? The study also intends to examine the difference between aluba and bullying, as well as masculinities that were constructed in the practice of aluba.

\section{Methodology}

In-depth interviews were conducted to achieve an understanding of the aluba experience and the subjective interpretations of aluba participants. In addition, film clips and news were collected from the internet for analysis. Twenty-five males were interviewed, including some who never participated in aluba, and others who have participated in aluba to varying extents. We interviewed both heterosexual and gay men, and males with gender consciousness were also recruited. The average interview lasted approximately 90 minutes. The interview questions included: When do you hear this term 'aluba'?; What is your experience with aluba (as alubaer, alubaee, and onlookers)?; What is the difference between alubaing others and being alubaed?; What is the process of a typical aluba (timing, role selection, process and ending)?; Have you been involved in a failed aluba?; Is aluba related to sex?; Are there other activities/games related to sex?; What kinds of people would or would not participate in aluba?; Do these groups possess specific characteristics?; What proportion of a class has participated in aluba?; Will aluba affect day-to-day human relationships?; What is the position of females in aluba?; and What attitudes do school staff have towards aluba and do they intervene?

The internet has many video clips of aluba incidents. These clips are uploaded by senior high school males, and some display sophisticated editing and post-production. The large number of aluba videos released by participants (including the alubaee) attests to the performance and ritualistic nature of aluba. As such, it makes a suitable subject for filming and photography, as opposed to genuine adolescent violence, which is not worthy of treasured remembrance. We analysed the narrative construction of the short films to see how the sense of play is created and enriched by the pictures and the accompaniment of caption and sound. The analysis can offer an insight into the participants' interpretation and understanding of 'getting high' (on excitement), as well as elements in the pleasure of play which are intentionally heightened. At the time of writing 77 news entries related to aluba could be found in the online archives of the United Daily News newspaper (UDN.com).

\section{Description of a typical aluba}

Aluba became popular in Taiwanese high schools in the 1980s, and used to be called 'pole fucking' (in colloquial Taiwanese). It is a vulgar term and, as such, can hardly be shouted aloud in public. Conversely, 'aluba' sounds almost exotic when it is exclaimed, like some secret that requires decoding. The aluba game is basically played by three or four people who grab another by his limbs, spread his legs, and make a play of 
symbolically pushing his genitals against a pole or other solid object. The person being 'alubaed' is expected to struggle and howl dramatically, while the onlookers cheer to generate greater excitement. The prop does not necessarily have to be a pole, and any available object will do, such as door frames, classroom signs, chairs, railings, and trees. However, interviewees explained that, by keeping the alubaee at the correct angle at the moment of impact, his genitals do not actually even strike the pole-like object and that the most likely source of pain to the alubaee is to the arms from being held too tightly. In fact, interviewees suggested that the greatest danger to the alubaee is being dropped or set down too quickly or carelessly.

\subsection{Roles in an aluba activity}

The primary participants in an aluba activity consist of: (1) the alubaee - the main character of the game; (2) the initiator - the participant who initially suggested the game (he is usually an alubaer, too); (3) the alubaers - generally three or four participants are responsible for grabbing the alubaee's arms and legs; (4) the shouters - people who clamour, shout, jeer, generate additional excitement and sometimes also provide suggestions for the alubaers to follow; (5) the safety guardian - occasionally additional participants are tasked with removing unwanted obstacles from the path of the alubaers and alubaee; (6) the human pole - in rare cases, when the participants could not find a pole or similar object, or when too many people participate in the game, one classmate will be asked to serve as a substitute for the pole.

The initiator must be sufficiently popular in the class that classmates will respond quickly to his suggestion. Most prefer to be the alubaers in that they gain a sense of group participation while enjoying the fun. Some prefer to shout on the sidelines. The shouters gain a sense of participation, but they do not need to expend any energy carrying the alubaee. Some people prefer to be the human pole since he is in the best position to watch the entire activity and watch the facial expressions of the other participants. Roles change regularly, though few people like to be alubaed. Even though the violence is simulated, the alubaee still runs a risk of injury and, at the very least, ends up dishevelled and embarrassed.

\subsection{The timing of aluba}

Aluba nearly always takes place between classes, during lunch, or after school. Interview subjects indicated that aluba can be planned ahead or occur spontaneously, with each type having its own characteristics. (1) Planned: planned aluba most frequently occurs on birthdays. If someone does not want to be alubaed by his classmates, he would let them know his birthday is during a school holiday. Some even wrote down non-existent days (e.g. 31 November) as their birthdays. Other common reasons for planned aluba include earning the top score on a test, winning an award, performing well on entrance exams, and being found in a romantic relationship. Retribution is also a common cause for planned aluba, with a frequent alubaee settling scores with his past tormentors. (2) Spontaneous aluba: spontaneous aluba occurs most frequently in response to a classmate saying something foolish. Alternatively, spontaneous aluba can occur in the heat of the moment, such as a winning relay team alubaing each other in turn. Actually, quality of performance does not seem to be a factor in prompting spontaneous aluba in that a student who hits three baskets in a row is as likely to be alubaed as someone who misses three in a row. In fact, aluba has become a normal 
part of high school daily life, and does not require a special event or occasion. Rather, aluba can be played whenever the mood strikes. One interviewee explained: 'any kind of circumstance can be used as a reason for aluba ... just like aluba is a thing we should really do'. In some cases, a student is chosen to be alubaed for no apparent reason, and roles can shift in the process without warning, resulting in an alubaer becoming the alubaee. These spontaneous acts are often described as 'The aluba God came for him today', and no other reason is required. Another interviewee noted that boys are sometimes alubaed simply because they have not been alubaed before or simply because 'he's owed'. In other words, there does not have to be a reason for aluba.

\subsection{The aluba process}

A typical aluba goes as follows:

(1) Setting the context - as mentioned above, aluba can be planned ahead or performed spontaneously.

(2) Initiating - the alubaee is identified.

(3) Establish control - the alubaee is caught by the alubaers.

(4) Execution - the alubaee should act as if he is resisting and struggling, and plead for mercy. The alubaers and the shouters clamour together to encourage more excitement (e.g. shouting 'One, two, attack!') and send the alubaee to the pole. Constant interaction and communication between the alubaee and alubaers makes the game more interesting.

(5) Conclusion: the aluba normally ends when the alubaers start to feel tired, the bell rings, or when someone comes to stop the game. The alubaers normally put the alubaee down head first, followed quickly by his legs. They then disperse in a hubbub, leaving the embarrassed alubaee behind to see to himself.

\section{Discussion and analysis}

The popularity of aluba seems to be unique to Taiwanese high schools. In the West, the closest thing to aluba is 'pole racking', as shown 10 minutes into the $1998 \mathrm{film}$, The Faculty. However, in that context, it is clearly intended to be bullying as a group of physically imposing males grab the smaller protagonist (played by Elijah Wood), ram him against a lamppost and toss him to the ground. Comments on relevant Yahoo! Groups indicate that pole racking is considered to be a painful form of high school or college initiation, ${ }^{1}$ and a high school forum on Facebook included the comment 'You have to be a complete loser and wimp to have that happen to you'.' However, in Taiwan, aluba is not an act of terror carried out by a rare few, but an essential part of campus culture shared by adolescent males.

\subsection{Is aluba bullying or hazing?}

When aluba is described to Western scholars, they nearly always point to literature on bullying and hazing. While definitions of bullying vary, there is a consensus view that it involves the repeated, intentional harming of one person by another where there is an imbalance of social and physical power (Coloroso 2004; Farrington 1993). The harmful behaviour can be physical (kicking and hitting), verbal (threats, ridicule or gossip), and 
social (isolation or exclusion) (Monks et al. 2009). Different roles have been distinguished among bullying participants, namely leader, assistant, reinforcer, bystander, defender, and victim. On campus, bullies and victims form a minority (about $2-$ $20 \%$ ), and some children can be both bully and victim. The risk factors associated with victims are a lack of close friends, an over-protective family, homosexuality, and mental and physical disabilities. Bullies tend to be angry, aggressive children who experience violence at home. In contrast, aluba participants (the alubaee and the alubaers) are not in the minority on campus, rather the opposite, and there is no clear imbalance of power between the alubaee and the alubaers, whose roles can be instantly swapped. Aluba is not about intentional harm, but an enactment of symbolic violence. The purpose of bullying is abuse, and the act is not a means for the bully to initiate the bullied into the 'we' group. However, aluba participants already belong to the 'we' group, or are using aluba to attempt such an initiation. The bully and the bullied do not swap roles, but 'One who alubas others will be alubaed by others', and rarely does anyone play only the part of the alubaer. Aluba can be a gesture of goodwill, with celebratory overtones, and the alubaee is often the easy-going/popular joker/ good sport in a group of friends - people who are truly quiet/serious/awkward are usually left alone.

Hazing differs from normal violent behaviour in that it is an initiation of an outsider into a fraternity through humiliation, punishment, endangerment, and other acts against the subject's will (such as being forced to consume large amounts of strong alcohol, eating unpleasant things, sleep deprivation, and even gang rape). In the past 30 years in the USA, 60 college students have died as a result of hazing, and it is now banned by law in most states (Gershel et al. 2003). Compared to the secret activities of hazing, aluba, though also a repeated tradition with significance of inclusion to 'we' group, is always done in the open; it is not a cruel physical or emotional trial, nor is it abuse. In light of the above, we will look instead at the literature on play and masculinity.

We believe that prior research (e.g. Kuo 2004) often overlooks aluba's play aspect, and focuses more on analysing the various power structures (e.g. the culture of cruelty among males, misogyny, and homophobia) than on what aluba 'means to the player'. It could be said that prior research is concerned instead with how aluba is perceived by society/families/individuals on the outside, to form a critical view of adolescent male peer culture. From injuries sustained in aluba, it is easy to regard aluba as an act connected with domination and oppressive force, thus simplifying the complexity of the play and attaching to it a negative cultural value. If, in line with Huizinga (1949/1998), we consider sport to be a ritualistic form of play, then it is conceivable that the serious injury of professional athletes did not label the 'playing' of sports with a negative culture value. As an interviewee explained with a direct analogy, 'Basketball is also a violent sport, with all that charging around the court, but we know that there are rules so, although players may bang into each other and get an accidental knock, it is still forbidden to hit someone directly with the ball'. His statement reveals the hidden rule of group dynamics in aluba: although fouls may be unavoidably committed (taking advantage of the chance to cause harm), such instances are rare and not encouraged. Interviewers mentioned the role of a 'safety guardian' as one responsible clearing the way of obstacles/dangerous objects and supporting the alubaers should they appear unsteady. The Complete Aluba Diary - a popular student-produced video clip showing aluba through the eyes of one of the alubaers - also pays attention to the risk of the play, twice mentioning the issue of pain in the captions. In other words, 
even in the excitement of boisterous fun, the alubaers are careful to avoid hurting the alubaee.

On the other hand, Yang proposed that the males seen as introverted risk 'being left out by their peers' $(2010,69)$. To the observer, it would appear that the alubaee is being physically coerced by his peers. But the results of this study indicated that the alubaee frequently gives his implicit consent. In other words, most of the aluba games are played by a group of male peers who have good mutual relationships. If it is played between unfamiliar peers or between antagonists, the laughter and positive peer interaction, which makes aluba fun, would disappear. A boy who chooses not to get involved is unlikely to be alubaed. Those who choose to participate are normally aware of the rule that 'One who alubas will be alubaed'. The boys never use aluba to isolate unwelcome classmates. On the contrary, no one would be interested in alubaing a classmate who has already been isolated.

\subsection{Aluba and sex/gender/sexuality}

Aluba shows the close connection of sex, gender, and sexuality. Aluba is played most frequently in male single-sex high schools. At co-educational schools aluba is popular while boys outnumber girls. In humanities and social sciences classes, which tend to have a majority of female students, the males are less likely to play aluba. Aluba is basically a game played among male peers without any female participants. Thus, it is particularly popular in male schools. In a co-educational school, the boys will try to avoid playing aluba in front of girls. According to interviews, female students generally look on aluba as a childish game, and they do not see what might be amusing about it. If someone is being alubaed nearby, most girls remain at their seats and ignore it, though some may show interest in the outcome. A few will intervene to stop the game to the boys' disappointment.

Evidently, aluba is an activity involving friendship among male peers and females are excluded. This activity also tries to eliminate feminine characteristics. The interviewees stressed that 'as men, we should celebrate birthdays with aluba. Cutting birthday cakes is too girlish'. Aluba is also used to verify the physical maleness of the alubaer and alubaee. Says one interviewee, 'The focus of aluba is on the penis. Aluba is performed to identify the participants' actual gender without taking off the pants'. Generally, a typical gender identification involves asking the less masculine males to take off their pants to reveal their penis. But the identification in aluba does not focus on the gender characteristics of the classmate. Instead, it is built on 'the alubaee's need to (pretend to) shout it is hurting him' and thus prove he possesses a penis. The suffering already contains a specific connotation, and the symbolic verification that the alubaee has a penis acts to reinforce the group identity. Thus, the game necessarily excludes the female. One male interviewee who has a high-pitched voice said the other boys in class treated him as a female and thus have no interest in alubaing him.

Almost every interviewee mentioned that none of the participants connects aluba to sex. In The Complete Aluba Diary (video clips), all five close-ups are of the face of the alubaee ('See how satisfied he looks'), suggesting that, while aluba superficially revolves around the genitals, in the actuality of play the interested gaze of the alubaers (camera/narrator) is on the facial expression of the alubaee, rather than his genitals the grimace, the rolled-back eyes can all be a source of pleasure. In other words it indicates no flow of sex/desire among the males who participate in aluba. But this does not necessarily mean it has no connection to sex. Instead, a great deal of fascination with 
and imagination of sexual ability is generated through aluba. When a pit is discovered on a coconut tree, senior students would tell the junior students that it is an achievement from past aluba games. The Complete Aluba Diary also depicts a warped stairway banister or the coincidental lighting of a streetlight during aluba as a sign of the participant's sexual ability, and this aspect could also contribute to enjoyment. In addition, some interviewees mentioned that some of the alubaees intentionally imitated the lewd moaning from Japanese adult films, thus allowing the alubaer to imagine that he is a heterosexual male watching an adult movie. The comical imitation of a woman achieving orgasm elicits laughter from all participants and thus raises the excitement level further.

Heterosexual males are extremely wary of the connection between aluba and homosexual desire. Compared to the 'butt crack swipe', 3 which involves one-onone direct touching of the genitals, aluba is communal and playful and, as such, dissociates itself from the suspicion of homosexuality. Aluba allows intimacy among male peers without damaging the heterosexual group identity (Kehily and Nayak 1997). Our interviewees note that it would be perverse for the alubaee to look genuinely pleased. For further clarification, we asked a few gay men about their attitude towards and experience with aluba. Most of them found aluba to be such an immature activity that they would never consider participating. As to whether it is possible to obtain pleasure from the physical contact in aluba, one interviewee said that although gay men may wish to have physical contact with other men while growing up, the desire is 'more subtle, not open', and the public and rough nature of aluba is contradictory to these expectations. However, some young gay men stressed that if a male classmate (heterosexual) he likes is being alubaed, they would have an urge to rescue him (but would not act on it) or would take satisfaction in seeing a novel facial expression on the classmate. If boys were aware of an openly gay classmate, they would not dare aluba him out of insecurity over boundaries, unless they are already very intimate with one another.

Aluba is a physical thing, a dirty joke told in action. According to the concept of emotional illiteracy proposed by Mac an Ghaill (1994), males lack the use of emotional language and a safe space to speak it. As one interviewee revealed, senior high school males want to make friends with one another, but do not know how, and the collective tomfoolery of aluba is adopted as a friendly gesture. Although some scholars (Nightingale 2001) argue otherwise, most research has indicated that, unlike the friendship of females, which is built on sharing, friendship among males is usually based on communal activities or play (e.g. Lyman 1987). It is interesting that while males need intimacy, they also require a clear-drawn emotional line between homosocial bonding and homosexuality (Kehily and Nayak 1997). The suspicion of homosexuality associated with intimate physical contact among men is only allayed in the context of sport (where masculinity is unquestioned) and play (outside the conventions of ordinary life) for the safe maintenance of one's heterosexual masculinity. Due to infrequent physical contact among males, aluba, with its physicality, can certainly promote closeness. One interviewee described aluba as a way for males to break free from the bounds of the body and become better acquainted, 'a bit like communal showering or peeing together outdoors'. Mutual alubaing can give individuals a feeling of belonging to the same group. However, the aluba process involves the pulling and dragging of body parts, and all kinds of vulgar language, and rarely involves real communication or the sharing of inner feelings. 


\subsection{The 'high' culture of aluba and the construction of masculinities}

Play among males requires a foundation of social bonding, and it is through play that social bonds are continuously reaffirmed (Lyman 1987). Once you have participated in aluba (either as an alubaer or shouter), then you must be prepared to be alubaed yourself. The interviewees called this 'repaying debts' and believe in that 'he who likes to aluba others but refuses to be alubaed is taking advantage of others. Everyone will hate you ... they won't invite you to do anything with them in the future'.

As pointed out by Kehily and Nayak (1997), the most common form of interaction among schoolboys is ritualistic games of initiation rich in verbal and physical aggression. In the competitive use of language and body, play becomes the arena for competing masculinities, and the techniques of these rituals are aimed at placing the other person in a position of vulnerability. With aluba, collective climax is attained through the symbolic attack on the most vulnerable part of the male body (the genitals). One interviewee repeatedly stressed the importance of reaching a 'high"4 together, via the fear-inspired thrill associated with the assault on the genitals (although the fear is largely simulated). Similarly, because a groin attack is the most effective form of aggression against men and everyone knows how painful it would be if the act of aluba were real, even when the agony is faked, 'seeing someone writhe in pain is still very satisfying'. However, in aluba the action of attacking the genitals is just a symbolic performance. Unlike smashing someone's face with a pie, or throwing someone into a pond as a birthday prank, in aluba the act of physical harm against the alubaee is entirely simulated with no actual violence. The boys' response to aluba is a mixture of tears and laughter, showing that they felt happiness despite the pain. If the alubaee were really suffering, it would not be fun for anyone.

Play is a test of masculinity and male bonding, and aluba serves to test whether the alubaee can take the risk (whether he has the nerve) and place his body in the control of the alubaers (whether he trusts his mates). As one interviewee said, aluba tests a person's tolerance as well as the strength of friendship in a group. Duelling among lads marks out the boundary of what is bearable in friendship, and identifies those that belong to the peer group, separating the 'alrights' from the 'wallies' who are to be excluded (quoted from Kehily 2007). Lyman (1987) also notes the important masculine value of 'being cool', and that in the world of men, jokes/humour is part of the male pedagogy that teaches the control of emotions.

The main character of any aluba activity is the alubaee. The alubaee's name could be used to define a particular aluba game, while the alubaer's appearance is less clear. It seems that the alubaee's body is being controlled by the alubaers, but at the same time, he is also being worshipped. Although nobody would compete to be alubaed the greatest number of times, the alubaee generally has an excellent relationship with his peers. An interviewee said about being alubaed, 'I don't think it's a loss of male dignity. Instead, they have built a stage for me and allowed me to be the centre of public attention'. Overall, the pleasure gained from aluba is group-oriented. The individual gains security from his group and the group gains a sense of identity. Normally, competition does not come from individuals within the group. The competition comes from other groups (such as other classes). Sometimes aluba is played outside a neighbouring classroom and the classes would compete with each other to determine which class plays better. If the alubaee is very popular in the whole school, they might deliberately play aluba in the public area downstairs to attract the attention of students in other classes. 


\subsection{The educational context of aluba}

As a form of 'high' culture among adolescent males, aluba is exciting because it contrasts with the unexciting life of senior high school males. In Kehily and Nayak (1997), humour (in its broadest sense) is a survival strategy in the oppressive institution of the school, a means of dealing with difficulties on campus (boredom, ceremony, routine, rules and oppression) by putting away the conventions of everyday school life for the sake of emotional therapy. The supportive conditions for the prevalence of aluba in Taiwanese high schools include: (1) Credentialism: study is the major focus for the high school students in Taiwan. The class schedule is arranged from morning to evening, with just a few 10-minute intervals between each class. Many students are required to study in cram schools or study centres after school. Aluba can be a conversion from the mood of study. In addition, the high contrast of hard-working students playing dirty games could also create pleasure. (2) Most universities, junior high schools, and elementary schools in Taiwan are co-educational schools. But most high schools are still segregated, especially the prestigious schools. Moreover, in Taiwanese high schools, each class of approximately 40 students stays in its assigned room, with each student having his own permanently-assigned seat. Therefore, the classroom is the main living space for the students. Deep friendships can be easily built in each class unit by spending time together from morning to evening. Activities such as playing cards and chatting tend to only involve small numbers of people, and these activities are rather static. In contrast, aluba often involves more than 10 participants and it is a game that can be played in the classroom, corridor, and other outdoor spaces, thus creating shared group excitement. (3) Adolescents are curious about sex. Compared to US high school students who readily interact with members of the opposite sex, Taiwanese boys have relatively limited interaction with female students and satisfy their curiosity primarily by searching for pornographic websites. Schools in Taiwan usually have explicit policies discouraging heterosexual dating, even in the co-educational schools. According to the US Centers for Disease Control and Prevention (2007), 47.8\% of US high school students reported having had sexual intercourse, while a similar study in Taiwan reported that about $20 \%$ of the senior high school students have had sexual intercourse, ${ }^{5}$ with even lower figures at the more prestigious schools. In addition, seeing a tall and strong male muttering and moaning obscenely presents a source of pleasure from the high contrast. (4) Minimal logistical requirements: boys require different activities to vent their physical energy. Aluba allows them to do this in a way which has very low time and space requirements and it can be performed without any prop (pole-like objects exists everywhere in the schoolyard) and specific space requirements. Indeed, it can be done nearly anywhere, anytime, by any small group. So aluba could easily satisfy the need for collective entertainment during the boys' boring and monotonous school life.

\subsection{Media representation of aluba}

Public awareness of aluba comes primarily through news reports. The 77 news entries collected were divided into the following categories: (1) male film and television actors playing aluba or recalling aluba experiences from high school; (2) boys suffering physical injuries from playing aluba; (3) other news items related to various male genital injuries by other causes, which then touch on the potential danger of playing aluba. The general impression established by the media is that aluba is a violent game with 
a high risk of genital injuries. Indeed, the outsiders seem to feel the alubaee's pain (while the parents are more concerned about their son's ability to carry on the family line). However, as noted above, aluba is never performed with the intention to injure, and what injuries do occur tend to result from the alubaer's gripping the alubaee's arms too tightly or from putting him down too quickly afterward.

\section{Conclusion}

Aluba is a popular activity among adolescent male peers that fulfils the needs for collective entertainment during the monotonous school life.

In the adolescent stage, most teenagers are curious about sex, and belonging to a peer group is also important for their identity formation. Aluba focuses group interaction on the genitals and, through pretending to attack each other's genitals, all of the participants are reassured of their male identity. The potential for pain indicates that the person has male genitals, and so females are excluded from this activity. Moreover, the vigorous movement and spaces used in the activity are marked as masculine, and can contribute to a sense of superior sexual ability.

Credentialism is an important value for Taiwanese people. Therefore, study is the major focus for high school students. Forty students spend a whole day in the same classroom, and a sense of brotherhood can develop easily among boys in the same class. Aluba is a group activity in which boys show their friendship through bodily contact and shouting. The contrast between 'stupid' play and hard study gives them the opportunity to break school rules. The flexibility of play makes it possible to involve more than 10 people at a time, and the minimal time and space requirements make it easy to do as an impromptu activity. In addition, the participation of shouters and onlookers creates a 'high' (exciting) sensation around aluba.

Adolescent male attitudes and experiences of sex, the value of collectivity and credentialism, and the long-term sharing of collective space all contribute the emergence of aluba as a uniquely male peer activity in high school settings in Taiwan.

\section{Acknowledgements}

The authors would like to give thanks for the help of the 25 interviewees and four research assistants (Wen, Tin, Bo-Han, and Bo-Hau), the useful comments of two reviewers, and the financial support of National Science Council (NSC 99-2410-H-002-161).

\section{Notes}

1. See http://groups.yahoo.com/group/poleracking/summary.

2. See http://www.facebook.com/topic.php?uid=2226030667\& topic $=2353$.

3. Using one hand from behind to touch and swipe another guy's genital parts.

4. In Chinese, 'high' means feeling excited. It has nothing to do with the difference between high culture and popular or low culture.

5. See http://www.doh.gov.tw.

\section{References}

Coloroso, Babara. 2004. The bully, the bullied, and the bystander. New York: HarperResource. Connell, R.W. 2002. Studying men and masculinity. Resources for Feminist Research 29, no. 1-2: $43-56$. 
Connell, R.W. 2005a. Growing up masculine: Rethinking the significance of adolescence in the making of masculinities. Irish Journal of Sociology 14, no. 2: 11-28.

Connell, R.W. 2005b. Hegemonic masculinity: Rethinking the concept. Gender and Society 19: $829-59$.

Farrington, David. 1993. Understanding and preventing bullying. In Crime and justice: A review of research. ed. Michael Tonry, 381-458. Chicago: The University of Chicago Press.

Gershel, Jeffrey C., Rachel J. Katz-Sidlow, Eric Small, and Stephanie Zandieh. 2003. Hazing of suburban middle school and high school athletes. Journal of Adolescent Health 32: 333-5.

Gilbert, Rob, and Gilbert Pam. 1998. Masculinity goes to school. London: Routledge.

Huizinga, Johan. 1949/1998. Home ludens: A study of the play-element in culture. London: Routledge.

Johnson, Allan G. 2005. The gender knot: Unraveling our patriarchal legacy. Philadelphia: Temple University Press.

Kehily, Mary J. 2007. Playing. In Understanding youth: Perspectives, identities and practices. ed. Mary J. Kehily, 249-81. London: Sage.

Kehily, Mary J., and Anoop Nayak. 1997. 'Lads and laughter': Humor and the production of heterosexual hierarchies. Gender and Education 9: 69-87.

Kuo, Y.-L. 2004. A pleasant sensation from rubbing?: The masculinity construction of Aluba, Master's thesis, Graduate Institute of Building and Planning, National Taiwan University. [In Chinese.]

Lyman, Peter. 1987. The fraternal bond as a joking relationship: A case study of the role of sexist jokes in male group bonding. Changing men: New directions in research on men and masculinity. ed. Michael S. Kimmel, 148-63. Newbury Park, CA: Sage.

Mac An Ghaill, Mairtin. 1994. The making of men: Masculinities, sexualities and schooling. Philadelphia: Open University Press.

Monks, Claire P., Peter K. Smith, Paul Naylor, Christine Barter, Janet L. Ireland, and Iain Coyne. 2009. Bullying in different contexts: Commonalities, differences and the role of theory. Aggression and Violent Behavior 14: 146-56.

Nardi, Peter M. 1992. Seamless souls: An introduction to men's friendship. In Men's friendships. ed. Peter M. Nardi , 1-14. Newbury Park, CA: Sage.

Nightingale, Richard. 2001. Men have friends, too!. In Men and masculinity: A text reader, ed. Theodore F. Cohen, 146-7. Belmont, CA: Wadsworth.

Seidler, Victor J. 2006. Young men and masculinities: Global cultures and intimate lives. London: Zed Books.

Swain, Jon. 2005. Masculinities in education. In Handbook of studies on men \& masculinities, ed. Michael S. Kimmel, Jeff Hearn and Robert W. Connell, 213-29. London: Sage.

US Centers for Disease Control and Prevention. 2007. Trends in the prevalence of sexual behaviors (PDF). The National Youth Risk Behavior Survey (YRBS) 1991-2007. http://www. cdc.gov/HealthyYouth/yrbs/pdf/yrbs07_us_sexual_behaviors_trend.pdf (accessed March 8, 2010).

West, Candace, and Don Zimmerman. 1987. Doing gender. Gender and Society 1: 125-51.

Whitehead, Stephen M. 2002. Men and masculinities. Cambridge: Polity.

Yang, H.-C. 2010. Becoming a male: The road of learning masculinity. In Gender education, ed. You M.H., H.C. Yang and C.L. Yang, 51-76. Taipei: Far Du. [In Chinese.]

Youdell, Deborah. 2005. Sex-gender-sexuality: How sex, gender and sexuality constellations are constituted in secondary schools. Gender and Education 17: 249-70.

Young, Iris M. 2005. On female body experience: 'Throwing like a female' and other essays. New York: Oxford University Press. 